\title{
Multi-criteria Group Decision Supplier Selection Problem using Fuzzy TOPSIS Based Approch
}

\author{
Akram ZOUGGARI and Lyes BENYOUCEF \\ INRIA Nancy-grand Est, COSTEAM Project, Bat. A, Ile du Saulcy, 57000, Metz, France \\ \{akram.zouggari, lyes.benyoucef\}@inria.fr
}

\begin{abstract}
This paper presents a new decision making approach for group multi-criteria supplier selection problem, which clubs supplier selection process with order allocation for dynamic supply chains to cope market variations. More specifically, the developed approach imitates the knowledge acquisition and manipulation in a manner similar to the decision makers who have gathered considerable knowledge and expertise in procurement domain. Fuzzy-AHP method is used first for supplier selection through four classes (CLASS I: Performance strategy, CLASS II: Quality of service, CLASS III: Innovation and CLASS IV: Risk), which are qualitatively meaningful. Thereafter, using simulation based fuzzy TOPSIS method, the criteria application is quantitatively evaluated for order allocation among the selected suppliers. As a result, the approach generates decision-making knowledge, and thereafter, the developed combination of rules for order allocation can easily be interpreted, adopted and at the same time if necessary, modified by decision makers. To demonstrate the applicability of the proposed approach, an illustrative example is presented and the results analyzed.
\end{abstract}

Keywords: Supplier selection, fuzzy AHP, fuzzy TOPSIS, knowledge, multi-criteria, group decision.

\section{Introduction}

Nowadays, among various supply chain-related activities, the procurement of goods and services is playing an increasingly important role as a result of the globalisation of the economy. Purchasing expenses can consume as much as $60 \%$ or more of business' revenues. In many settings, supplier selection is a crucial strategic decision that has long-term impacts on a company's profitability and efficiency.

Generally for most of the procurement/purchasing departments, supplier selection is considered as a fivephase process starting from the realization of the need for a new supplier; determination and formulation of decision criteria; pre-qualification (initial screening and drawing up a shortlist of potential suppliers from a large list); final supplier selection; to the monitoring of the suppliers selected (i.e., continuous evaluation and assessment). In order to ensure an uninterrupted supply of products, it has been observed that more than one supplier is normally available for each product. Periodic evaluation of supplier quality is carried out to ensure relevant quality standards for all incoming products are met. The key objective is to purchase the right quality of product in the right quantity from the right source at the right time and at reasonable price.

This paper presents a novel approach for automatic fuzzy based knowledge acquisition, which clubs supplier selection process with order allocation. More specifically, the developed approach imitates the knowledge acquisition and manipulation in a manner similar to the decision makers who have gathered considerable knowledge and expertise in procurement domain. As per this concept, those decision criteria for supplier selection are considered first through four classes (CLASS I: Performance strategy, CLASS II: Quality of service, CLASS III: Innovation and CLASS IV: Risk), which are qualitatively meaningful. Thereafter, using fuzzy logic, the criteria application is quantitatively evaluated. As a result, the approach generates decision-making knowledge, and thereafter, the developed combination of rules for supplier selection with order allocation can easily be interpreted, adopted and at the same time if necessary, modified by decision makers. The rest of the paper is organized as follows: Section 2 presents state of art of supplier selection problem. Section 3 presents problem description and proposed approach. Section 4 illustrates some of the experimental results. Section 5concludes the paper with some perspectives.

\section{Supplier selection problem: State of the art}

\subsection{Factors impacting supplier selection decisions}

A number of research works have been published in the last decades emphasized the strategic importance of the supplier selection process and evaluated the relative importance of the most used selection criteria and subcriteria. Van der Rhee et al. [10] explored how executives' trade-off amongst various dimensions when selecting a supplier. An empirical study is presented to assess the marginal trade-off for cost, delivery performance, flexibility, and value-added service/support in a supplier selection process using a market utility-based approach (DCA). Specifically, the three objectives are: (i) How do managers trade-off between price and other competitive criteria in supplier selection process, given acceptable quality?, (ii) What is the relative importance of value-added service and support when selecting suppliers, given acceptable quality?, and How do trade-offs in the supplier selection 
process differ across cultural/national regions?. Kannan and NoorulHaq [11] analyzed the interaction of criteria and sub-criteria that are used to select suppliers for the built-in-order supply chain environment. They presented an approach using Interpretive Structural Modeling (ISM) methodology to identify, rank and find out the interaction among the criteria and sub-criteria. Moreover, they stated that (i) business structure is the key criterion in selecting the supplier for the considered industry, (ii) services have strong drive power and weak dependence power, (iii) both quality system and adherence to quality tools are the key sub-criteria in the quality criteria. They have very strong driving power and dependence power, (iv) criteria such as quality and delivery have very low dependence and driving power, (v) engineering capability criterion has high dependence and low driving power, and (vi) business structure and service have the high dependence and high driving power.

\subsection{Existing computational intelligent approaches}

Wu et al. [15] proposed a two-stage integrated multiobjective decision-making approach using analytic network process (ANP) and mixed integer programming (MIP) to select suppliers when the bundling strategy existed. Lee et al. [16] presented a fuzzy multiple goal-programming (FMGP) model to help downstream companies to select thin film transistor liquid crystal display (TFT-LCD) suppliers for cooperation. Moreover, Amid et al. [17] developed a fuzzy weighted additive and mixed integer multiobjective linear programming model for the supplier selection problem under price breaks that depend on the sizes of order quantities. The model aggregates weighted membership functions of objectives to construct the relevant decision functions, in which objectives have different relative importance. To evaluate and select the most suitable suppliers for a telecommunication company in the GSM sector, Onüt et al. [18] proposed an integrated fuzzy analytic network process (FANP) and fuzzy technique for order performance by similarity to ideal solution (FTOPSIS) methodology.

Sanayei et al. [14] proposed an integrated approach using multi-attribute utility theory (MAUT) and linear programming for rating and selecting the best suppliers, and defining the optimum order quantities among selected ones in order to maximize the quantity of purchase from the desired suppliers.

\subsection{Why the need of a new approach?}

Based on a synthesis of the literature and our expertise, gained from literature review and involvement with industrial partners such as Renault, Fiat, Hi-Tech, Profactor, VTT, Robosoft, Schneider Electric, etc. in the European projects respectively Growth-ONE and I*PROMS, the motivations for a new approach are as follows:
1. The majority of the existing approaches/models are based on functional criteria like quality, price, delivery time, etc., and does not take into account the repercussions of the company strategy on the decisions by taking into account several novel criteria such as innovation, flexibility, risk, agility, responsiveness, etc. [1][2][5].

2. The multi-criteria aspect of the supplier selection problem is essential when we deal with a global approach [2][5].

3. The supplier selection problem is a decision or a set of decisions, which requires the intervention of different services of the company [2][5].

4. If a supplier cannot satisfy a minimal threshold compared to certain criterion, it cannot be selected in spite of its possible effectiveness with respect to other criteria.

5. There are several constraints to take into account. In addition, if the company would wish several suppliers, it must select suppliers and the order allocation strategy. The current approaches cannot cover the various aspects of the supplier selection problem with order allocation [2][5][7].

6. The future behaviors of the suppliers and the environment are uncertain. Consequently, it is difficult to assign a fixed mark to the suppliers with respect to a criterion.

7. An approach, which can take into account all the characteristics of the problem, the strategy of the company, the multi-actors aspect, the subjective and objective criteria, the constraints of suppliers and customer, etc., is a lack in the literature [9].

\section{Problem description and proposed approach}

\subsection{Problem setting}

Our supply chain comprises of a set of $\mathrm{K}$ potential suppliers, a unique distribution center (DC) and a unique market (customer). Each supplier is connected to the DC by a single transportation link. The transportation activity is taken care by the sub-criteria related to the quality of delivery. Our problem consists of two sub-problems. The first sub-problem concerns with the selection of suppliers during a fixed decision horizon called 'selection horizon', which is by assumption more than 1 year. Where, the second subproblem deals with the order allocation strategy among the selected suppliers. A supplier that is selected in a given 'selection horizon' is not necessarily selected in another one; a new list of potential suppliers is created at the end of each 'selection horizon' for the next. The 'selection horizons' are independent.

Market: Entity where the initial demands of a single product type are generated and fulfilled finally by deliveries from the distribution center (DC). The demand could be modeled as a sequence of specific market orders (obtained from historical records) or as an aggregated demand during a period following any distribution law. Attributes related to this entity are 
respectively, demand quantity, demand frequency and expected delivery date.

Distribution center (DC): Intermediate entity between suppliers and market, the DC plays a critical role in our case. The inventory held in the DC is replenished according to some given inventory control policies. Several classical inventory control policies, such as base stock, lot for lot, etc., are defined and implemented in the simulation package. It places purchasing orders to suppliers and receives deliveries from suppliers through transportation links. Main attributes are respectively, storage capacity, handling capacity, operation cost and inventory cost. Relevant costs are inventory holding cost, ordering cost, and over-capacity cost.

Supplier: Source entity where material flow originates. It provides raw materials, components, semi-finished and even final products to the DC, which further on the basis of its inventory control policy, will deliver them to the market. We are not interested in the process of manufacturing the products by the suppliers. Furthermore, there is no explicit capacity limitation for suppliers.

\subsection{Decision criteria}

For ranking the potential suppliers the following three terminologies are used:

1. Satisfactory: A supplier who has sustained superior performance by enhancing his abilities to address the marketplace is considered satisfactory. It provides the best value and is the one with whom the company (i.e. DC) wants to focus for as much business as possible.

2. Conditional: A supplier who has an acceptable level of performance but may fall short of superior performance levels required for a preferred rating.

3. Unsatisfactory: A supplier whose performance is poor or commitment to the company (i.e. DC) is weak. This supplier will not be considered in the selection. The DC feels that doing business with this supplier decreases his efficiency and position in the existing challenging and dynamic market.

\section{C1: Performance Strategy}

- Quality : Percentage of products which qualify the expectations of the DC in terms of quality

- Pricing : Unit price communicated by each potential supplier.

- Age and position in the market : Age of the supplier and its position in the market in terms of number of customers or in terms of the transaction amounts.

- Environmental engagement : Percentage of supplier's profit dedicated to the environmental safety.

\section{C2: Quality of service}

- Delivery: Percentage of the products delivered in time guaranteed by the supplier.

- $\quad$ Service after sale: Response time to any service after sale action, guaranteed by supplier.

- Preventive actions: Necessary actions, which are defined and planned by the supplier in order to keep the quality of service highest.

- Corrective actions: Necessary actions, which are defined and not planned by supplier in order to keep the quality of service highest.

\section{C3: Innovation}

- Research and development: Percentage of the total supplier's profit dedicated to $R \& D$ activities.

- $\quad$ Service innovation: Percentage of total supplier's profit dedicated to innovation.

\section{C4: Risk}

- Geographical location: Supplier location, physical and social status.

- Political and economical stability: Political status of the supplier's country and its nature towards the business policies pay affecting the long term relationship.

\subsection{Proposed approach}

\section{- Overview}

The proposed approach consists of mainly four stages I, II, III and IV.

\section{Stage I: Aggregation of group decisions \\ Begin}

Step1: Aggregation of the pre-wise comparison matrix

End.

Step2: Calculate the consistency ratio(CR)

\section{Stage II: Suppliers selection \\ Begin}

Step1: Select the used criteria for selecting the best suppliers among criterion I, criterion II, criterion III and criterion IV.

Step2: Call fuzzy-AHP method.

End.

Step3: Provide the lest of selected suppliers.

\section{Stage III: Simulation \\ Begin}

Step1: Initialize the data, market configuration; storage political; simulation parameters.

Step2: Call the knowledge-based simulation platform.

Step3: Update the database (i.e. new values of criteria; evaluation of the stock level, etc.).

End.

\section{Stage IV: Order allocation \\ Begin}

Step1: Select the criteria for order allocation respectively cost, quality and delivery. 
Step2: Initialize the data: new values of criteria; list of suppliers.

Step3: Call the fuzzy-TOPSIS.

Step4: Update the database (i.e. order allocation of End. each supplier).

Stages II, III and IV use the same knowledge-based platform, which consists of four modules, respectively, the Suppliers selection module; order allocation module; simulator and rules modules (see Figure 1). A triangular fuzzy membership function (TFN) is used for the fuzzification and defuzzification, $a\left(l_{i}, m_{i}, u_{i}\right)$. Five linguistics variables are used to assess the importance weights: very high $(\mathrm{VH})$, high $(\mathrm{H})$, medium $(\mathrm{M})$, poor (P) and very poor (VP), table 1.

\begin{tabular}{|l|c|c|c|}
\hline & $l_{i}$ & $m_{i}$ & $u_{i}$ \\
\hline VH & 8 & 9 & 10 \\
V & 6 & 7 & 8 \\
M & 4 & 5 & 6 \\
P & 2 & 3 & 4 \\
VP & 0 & 1 & 2 \\
\hline
\end{tabular}

Table 1: linguistics variables and fuzzy values.

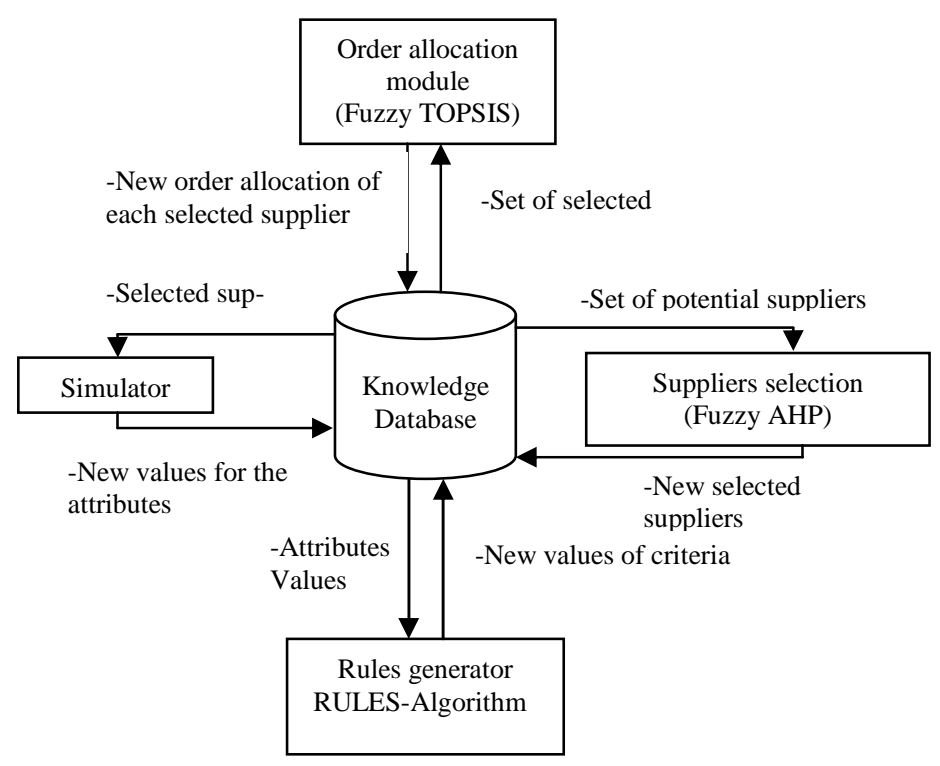

Fig. 1 : Knowledge-based simulation platform architecture

\section{Experimental results and analysis}

Ten potential suppliers are considered where the number of suppliers to select is fixed to four. Five decision maker( $\mathrm{DM}_{1}, \mathrm{DM}_{2}, \mathrm{DM}_{3}, \mathrm{DM}_{4}$ and $\left.\mathrm{DM}_{5}\right)$ given pre-wise comparison matrix, table 2-6. Each three months, new orders allocation rates are calculated.

\begin{tabular}{|c|c|c|c|c|}
\hline & $\mathrm{C} 1$ & $\mathrm{C} 2$ & $\mathrm{C} 3$ & $\mathrm{C} 4$ \\
\hline $\mathrm{C} 1$ & 1 & $\mathrm{vh}$ & $\mathrm{vh}$ & $\mathrm{vh}$ \\
$\mathrm{C} 2$ & $1 / \mathrm{vh}$ & 1 & $\mathrm{~m}$ & $\mathrm{~h}$ \\
$\mathrm{C} 3$ & $1 / \mathrm{vh}$ & $1 / \mathrm{m}$ & 1 & $\mathrm{vh}$ \\
$\mathrm{C} 4$ & $1 / \mathrm{vh}$ & $1 / \mathrm{h}$ & $1 / \mathrm{vh}$ & 1 \\
\hline
\end{tabular}

Table 2: $\mathrm{DM}_{1}$ fuzzy comparison matrix of criteria

\begin{tabular}{|c|c|c|c|c|}
\hline & $\mathrm{C} 1$ & $\mathrm{C} 2$ & $\mathrm{C} 3$ & $\mathrm{C} 4$ \\
\hline $\mathrm{C} 1$ & 1 & $\mathrm{vh}$ & $\mathrm{h}$ & $\mathrm{vh}$ \\
$\mathrm{C} 2$ & $1 / \mathrm{vh}$ & 1 & $\mathrm{~m}$ & $\mathrm{~h}$ \\
$\mathrm{C} 3$ & $1 / \mathrm{h}$ & $1 / \mathrm{m}$ & 1 & $\mathrm{vh}$ \\
$\mathrm{C} 4$ & $1 / \mathrm{vh}$ & $1 / \mathrm{h}$ & $1 / \mathrm{vh}$ & 1 \\
\hline
\end{tabular}

Table 3: $\mathrm{DM}_{2}$ fuzzy comparison matrix of criteria

\begin{tabular}{|c|c|c|c|c|}
\hline & $\mathrm{C} 1$ & $\mathrm{C} 2$ & $\mathrm{C} 3$ & $\mathrm{C} 4$ \\
\hline $\mathrm{C} 1$ & 1 & $\mathrm{~m}$ & $\mathrm{vh}$ & $\mathrm{h}$ \\
$\mathrm{C} 2$ & $1 / \mathrm{m}$ & 1 & $\mathrm{~m}$ & $\mathrm{~h}$ \\
$\mathrm{C} 3$ & $1 / \mathrm{vh}$ & $1 / \mathrm{m}$ & 1 & $\mathrm{~m}$ \\
$\mathrm{C} 4$ & $1 / \mathrm{h}$ & $1 / \mathrm{h}$ & $1 / \mathrm{m}$ & 1 \\
\hline
\end{tabular}

Table 4: $\mathrm{DM}_{3}$ fuzzy comparison matrix of criteria

\begin{tabular}{|c|c|c|c|c|}
\hline & $\mathrm{C} 1$ & $\mathrm{C} 2$ & $\mathrm{C} 3$ & $\mathrm{C} 4$ \\
\hline $\mathrm{C} 1$ & 1 & $\mathrm{vh}$ & $\mathrm{h}$ & $\mathrm{h}$ \\
$\mathrm{C} 2$ & $1 / \mathrm{vh}$ & 1 & $\mathrm{~m}$ & $\mathrm{M}$ \\
$\mathrm{C} 3$ & $1 / \mathrm{h}$ & $1 / \mathrm{m}$ & 1 & $\mathrm{H}$ \\
$\mathrm{C} 4$ & $1 / \mathrm{h}$ & $1 / \mathrm{m}$ & $1 / \mathrm{h}$ & 1 \\
\hline
\end{tabular}

Table 5: $\mathrm{DM}_{4}$ fuzzy comparison matrix of criteria

\begin{tabular}{|c|c|c|c|c|}
\hline & $\mathrm{C} 1$ & $\mathrm{C} 2$ & $\mathrm{C} 3$ & $\mathrm{C} 4$ \\
\hline $\mathrm{C} 1$ & 1 & $\mathrm{~h}$ & $\mathrm{vh}$ & $\mathrm{m}$ \\
$\mathrm{C} 2$ & $1 / \mathrm{h}$ & 1 & $\mathrm{~h}$ & $\mathrm{~h}$ \\
$\mathrm{C} 3$ & $1 / \mathrm{vh}$ & $1 / \mathrm{h}$ & 1 & $\mathrm{vh}$ \\
$\mathrm{C} 4$ & $1 / \mathrm{m}$ & $1 / \mathrm{h}$ & $1 / \mathrm{vh}$ & 1 \\
\hline
\end{tabular}

Table 6: $\mathrm{DM}_{5}$ fuzzy comparison matrix of criteria

\subsection{Supplier selection (Fuzzy-AHP)}

Table 2 presents the aggregate comparisons matrix of criteria with respect to the overall objective (global supplier selection), for calculate this matrix we used the next formulation proposed by Buyukozkam and Feyzioglu[7] :

$l_{i j}=\min \left(l_{i j k}\right)$,

$m_{i j}=\left(\prod_{k=1}^{k} m_{i j k}\right)^{1 / k}$

$u_{i j}=\max \left(u_{i j k}\right)$ 


\begin{tabular}{|l|l|l|l|l|}
\hline & \multicolumn{1}{|c|}{ C1 } & \multicolumn{1}{c|}{ C2 } & \multicolumn{1}{c|}{ C3 } & \multicolumn{1}{c|}{ C4 } \\
\hline C1 $(1,1,1)$ & $(4,7.6,10)$ & $(6,8.1,10)$ & $(4,7.2,10)$ \\
C2 $(0.1,0.13,0.25)$ & $(1,1,1)$ & $(4,5.3,8)$ & $(4,6.5,8)$ \\
C3 $(0.1,0.12,0.16)$ & $(0.13,0.18,0.25)(1,1,1)$ & $(4,7.6,10)$ \\
C4 $(0.1,0.13,0.25)$ & $(0.13,0.15,0.25)(0.1,0.13,0.25)$ & $(1,1,1)$ \\
\hline
\end{tabular}

Table 7: Aggregate comparison matrix of criteria.

- Consistency index and consistency ratio

The consistency index is calculated by:

$$
C I=\frac{\lambda_{\max }-n}{n-1}
$$

Where $n$ is the number of criteria in our case $n=4$ and $\lambda_{\text {max }}$ it's calculated by normalisation of each column of the comparison matrix [3],[7].

The consistency ratio is comparison between consistency index and random consistency index, or in formula :

$$
C R=\frac{C I}{R C}
$$

The average random consistency index is shown in the table 7 .

\begin{tabular}{|l|l|l|l|l|l|l|l|l|l|l|}
\hline$n$ & 1 & 2 & 3 & 4 & 5 & 6 & 7 & 8 & 9 & 10 \\
\hline$R C$ & 0 & 0 & 0.58 & 0.9 & 1.12 & 1.24 & 1.32 & 1.41 & 1.45 & 1.49 \\
\hline
\end{tabular}

Table 7: Random consistency index $(R C)$.

In our example $\mathrm{n}=4 \mathrm{RC}=0.9$

$$
\begin{aligned}
& C I=\frac{4.12-4}{4-1}=0.04 \\
& C R=\frac{0.04}{0.9}=0.044<0.1
\end{aligned}
$$

Therefore, we decided to include this aggregate comparison matrix which it respect the condition $(\mathrm{CR}=0.044<0.1)$.

Using the extent analysis method [17], we have the following results where $\mathrm{Ai}$ corresponds to the fuzzy synthetic extent value with respect to criterion $C_{i}(i=1$, $2,3,4)$ and $M$ the minimum degree of possibility.

$A_{1}=(0.16,0.50,0.68)$

$A_{2}=(0.11,0.27,0.43)$

$A_{3}=(0.073,0.18,0.31)$

$A_{4}=(0.021,0.03,0.05)$
$M\left(A_{1} \geq A_{2}, A_{3}, A_{4}\right)=\min (1,1,1)=1$

$M\left(A_{2} \geq A_{1}, A_{3}, A_{4}\right)=\min (0.54,1,1)=0.54$

$M\left(A_{3} \geq A_{1}, A_{2}, A_{4}\right)=\min (0.33,0.7,0.1)=0.33$

$M\left(A_{4} \geq A_{1}, A_{1}, A_{3}\right)=\min (0.3,0.33,0.12)=0.12$

The weight vector $\mathrm{W}$ of the 4 criteria is given by $(0.5$, $0.27,0.16,0.7)$ where:

$$
w_{i}=\frac{M\left(\tilde{A}_{i} \geq \tilde{A}_{j} \mid j=1, \ldots, 4 ; j \neq i\right)}{\sum_{k=1}^{4} M\left(\tilde{A}_{k} \geq \tilde{A}_{j} \mid j=1, \ldots, 4 ; j \neq k\right)}
$$

Similarly, the corresponding weight vector of each subcriterion with respect to the four criteria and the corresponding weight vector of each supplier with respect to the sub-criteria are also calculated. At the end, we compute the weight of each supplier with respect to main four criteria (see Table 8).

\begin{tabular}{|l|c|c|c|c|c|c|c|c|c|c|}
\hline & $\mathbf{S}_{\mathbf{1}}$ & $\mathbf{S}_{\mathbf{2}}$ & $\mathbf{S}_{\mathbf{3}}$ & $\mathbf{S}_{\mathbf{4}}$ & $\mathbf{S}_{\mathbf{5}}$ & $\mathbf{S}_{\mathbf{6}}$ & $\mathbf{S}_{\mathbf{7}}$ & $\mathbf{S}_{\mathbf{8}}$ & $\mathbf{S}_{\mathbf{9}}$ & $\mathbf{S}_{\mathbf{1 0}}$ \\
\hline $\mathbf{W}$ & 0.08 & 0.13 & 0.1 & 0.11 & 0.73 & 0.12 & 0.09 & 0.07 & 0.094 & 0.07 \\
\hline
\end{tabular}

Table 8: W: supplier priority weight.

We can conclude that suppliers $S_{2}, S_{3}, S_{4}$ and $S_{6}$ are the best four suppliers among the list of ten potential suppliers.

\subsection{Simulation and knowledge management}

By assumption, the simulation horizon is one year (48 weeks) and for the order allocation horizon is three months (12 weeks). The DC inventory control policy is $(Q, s)$, where $Q=500$ units and $s=200$ units. Moreover, each week, the DC receives a certain demand quantity with respect to the market planning demand. Table 9 illustrates the evaluation of the delivery for each supplier given in linguistics values.

Tables 10 and 11 illustrate the training examples for respectively sub-criterions quality and price. Attributes related to quality are: quality of packaging, finishing and size, where for sub-criterion price, attributes are respectively price duty-free and duties. By assumption, 'I', 'a' and ' 1 ' correspond to "good" and 'II', 'b' and '2' correspond to "medium".

\begin{tabular}{|l|c|c|c|c|}
\hline Period id & $\mathrm{S}_{2}$ & $\mathrm{~S}_{3}$ & $\mathrm{~S}_{4}$ & $\mathrm{~S}_{6}$ \\
\hline Period 1 & $\mathrm{P}$ & $\mathrm{H}$ & $\mathrm{H}$ & $\mathrm{M}$ \\
Period 2 & $\mathrm{P}$ & $\mathrm{P}$ & $\mathrm{P}$ & $\mathrm{H}$ \\
Period 3 & $\mathrm{H}$ & $\mathrm{M}$ & $\mathrm{M}$ & $\mathrm{H}$ \\
Period 4 & $\mathrm{M}$ & $\mathrm{P}$ & $\mathrm{P}$ & $\mathrm{M}$ \\
\hline
\end{tabular}

Table 9: delivery linguistics evaluation values

The used training rules are respectively: 
- Quality

If Quality of packaging =I then Quality $=H$

If Finishing $=B$ then Quality $=M$

If Weight $=1$ then Quality $=V H$

- Price

If Price duty-free $=I$ then Price $=V H$

If Price duty-free $=I I$ then Price $=M$

If Duties $=1$ then Price $=H$

If Duties $=2$ then Quality $=M$

For each supplier and each delivery, new linguistics values are calculated for price and quality.

\begin{tabular}{|c|c|c|c|c|}
\hline Example & $\begin{array}{c}\text { Quality of } \\
\text { packaging }\end{array}$ & Finishing & Size & $\begin{array}{c}\text { Linguistics } \\
\text { values }\end{array}$ \\
\hline 1 & II & A & 1 & VH \\
2 & I & A & 2 & H \\
3 & I & A & 2 & H \\
4 & II & A & 2 & H \\
5 & II & A & 2 & M \\
6 & II & B & 2 & M \\
7 & II & a & 2 & VH \\
\hline
\end{tabular}

Table 10: training example for quality

\begin{tabular}{|c|c|c|c|}
\hline Example & Quality of packaging & Size & \\
\hline 1 & I & 1 & VH \\
2 & II & 2 & M \\
3 & II & 1 & H \\
\hline
\end{tabular}

Table 11: training example for price

After a simulation of one year of activities, for each supplier and each delivery, new linguistics values and fuzzy values are calculated for quality and price (see Table 17 and 19 for quality).

\subsection{Order allocation (Fuzzy-TOPSIS)}

Tables 12, 13 and 14 show the comparison matrix of the three criteria respectively price, quality and delivery, with respect to the overall objective (order allocation). FPIS (Fuzzy Positive Ideal Solution) and FNIS (Fuzzy Negative Ideal Solution) are also calculated [18].

$\operatorname{FPIS}\left(A^{*}\right)$ and $\operatorname{FNIS}\left(A^{-}\right)$are given by :

$A^{*}=\left(\tilde{v}_{1}^{*}, \ldots \tilde{v}_{n}^{*}\right)=[(1,1,1),(1,1,1),(1,1,1)]$

$A^{-}=\left(\widetilde{v}_{1}^{-}, \ldots \tilde{v}_{n}^{-}\right)=[(0.32,0.32,0.32),(0.21,0.21,0.21),(0.28,0.28,0.28)]$

\begin{tabular}{|l|l|l|l|l|}
\hline & S2 & S3 & S4 & S6 \\
\hline
\end{tabular}

\begin{tabular}{|ccccc|}
\cline { 4 - 5 } Price & $(0.375$, & $(0.35,0.5,0.65)$ & $(0.35,0.5,065)$ & $(0.375$, \\
& $0.55, . .925)$ & & & $0.55, . .925)$ \\
Quality & $(0.625$, & $(0.55,0.765,0.9)$ & $(0.55,0.765,0.9)$ & $(0.625$, \\
& $0.845,0.95)$ & & & $0.845,0.95)$ \\
Delivery & $(0.2,0.3,0.4)$ & $(0.4,0.6,0.8)$ & $(0.4,0.6,0.8)$ & $(0.3,0.4,0.5)$ \\
\hline
\end{tabular}

Table 12: fuzzy comparison matrix

\begin{tabular}{|c|c|c|c|}
\hline & Pricing & Quality & Delivery \\
\hline $\mathrm{d}\left(\mathrm{S}_{2}, A^{*}\right)$ & 0.23 & 0.33 & 0.92 \\
$\mathrm{~d}\left(\mathrm{~S}_{3}, A^{*}\right)$ & 0.35 & 0.40 & 1.10 \\
$\mathrm{~d}\left(\mathrm{~S}_{4}, A^{*}\right)$ & 0.45 & 0.45 & 0.80 \\
$\mathrm{~d}\left(\mathrm{~S}_{6}, A^{*}\right)$ & 0.27 & 0.30 & 045 \\
\hline
\end{tabular}

Table 13: distance between supplier Si and $A^{*}$

\begin{tabular}{|l|c|c|c|}
\hline & Pricing & Quality & Delivery \\
\hline $\mathrm{d}\left(\mathrm{S}_{2}, A^{-}\right)$ & 0.54 & 0.20 & 0.33 \\
$\mathrm{~d}\left(\mathrm{~S}_{3}, A^{-}\right)$ & 0.19 & 0.33 & 0.84 \\
$\mathrm{~d}\left(\mathrm{~S}_{4}, A^{-}\right)$ & 0.19 & 0.34 & 0.85 \\
$\mathrm{~d}\left(\mathrm{~S}_{6}, A^{-}\right)$ & 0.68 & 0.45 & 0.34 \\
\hline
\end{tabular}

Table 14: distance between supplier $\mathrm{Si}$ and $A^{-}$

Now, we can compute the closeness coefficients of the four selected suppliers as (Table 15):

$C C_{i}=\frac{d\left(\operatorname{supplier}_{i}, A^{-}\right)}{d\left(\operatorname{supplier}_{i}, A^{-}\right)+d\left(\text { supplier }_{i}, A^{*}\right)}$

\begin{tabular}{|c|c|c|c|c|}
\hline Supplier & $\mathrm{S}_{2}$ & $\mathrm{~S}_{3}$ & $\mathrm{~S}_{4}$ & $\mathrm{~S}_{6}$ \\
\hline$C C_{i}$ & 0.42 & 0.42 & 0.45 & 0.60 \\
\hline
\end{tabular}

Table 15: closeness coefficients

By normalizing $C C_{i}$, we calculate the order allocation $\left(\mathrm{O}_{i}\right)$ of each supplier. Table 16 illustrates the obtained results, the order allocation of each selected supplier for the 4 periods.

\begin{tabular}{|c|c|c|c|c|}
\hline Example & Period 1 & Period 2 & Period 3 & Period 4 \\
\hline $\mathrm{S}_{2}$ & 0.22 & 0.21 & 0.26 & 0.28 \\
$\mathrm{~S}_{3}$ & 0.22 & 0.26 & 0.21 & 0.16 \\
$\mathrm{~S}_{4}$ & 0.24 & 0.30 & 0.34 & 0.31 \\
$\mathrm{~S}_{6}$ & 0,32 & 0.23 & 0.19 & 0.24 \\
\hline
\end{tabular}

Table 16: order allocation for the four selected suppliers

\section{Conclusions and perspectives}


In this paper, we have presented new decision making approach for group multi-criteria supplier selection problem, which clubs supplier selection process with order allocation for dynamic supply chains to cope market variations. More specifically, the developed approach imitates the knowledge acquisition and manipulation in a manner similar to the decision makers who have gathered considerable knowledge and expertise in procurement domain. Some experimental results are presented to illustrate the applicability of the approach.

As a perspective for the future, we are making an effort in checking the practical implications of the proposed approach in the real life industrial problems for global supplier selection. Another important line of research can be using fuzzy pattern matching approaches and also the definition of other classes of criteria either specific to the considered case study or more generic for several sectors of industrial activities.

\section{References}

[1] Weber, C. A., Current, J. R. and Desai, A. Vendor selection criteria and methods. European Journal of Operational Research, $\mathrm{N}^{\circ}$. 50, pp. 2-18, 1991.

[2] Mobolurin Multi-hierarchical qualitative group decision method: consensus building in supplier selection. International conference on applied modeling, Simulation and Optimisation, USA, pp. 149152, 1995.

[3] Saaty, T.L. Decision Making for Leaders. The Analytic Hierarchy Process for Decisions in a Complex World. 1995/1996 ed., completely revised. RWS Publications, Pittsburgh, 1995.

[4] Muralidharan, C., Anantharaman, S. P. and Deshmukh, S. G. Vendor rating in Purchasing Scenario: A confidence Interval Approach. International Journal of Operations and Production Management, 10(2), pp. 1305-1325, 2001.

[5] Muralidharan, C., Anantharaman, S. P. and Deshmukh, S. G. A Multicriteria Group Decision making Model for Supplier Rating. The Journal of Supply Chain Management, 38(4), pp. 22-35, 2002.

[6] Chan, F. T. S. Interactive selection Model for supplier selection process: an analytical hierarchy process approach. International Journal of Production Research, 41(15), pp. 3549-3579, 2003.

[7] Büyüközkam, G., \& Feyziog lu, O.. A fuzzylogic-based decision-making approach for new product development. International Journal of Production Economics, 90, 27-45, 2004.

[8] Deng, S.J. and Elmaghraby, W. Supplier Selection via Tournaments. Production and Operations Management, 14(2), pp. 252-267, 2005.

[9] Chan, F.T. S., Kumar, N., Tiwari, M. K., Lau, H. C. W. and Choy, K. L. Global supplier selection: a fuzzy-AHP approach. International Journal of Production Research, pp. 1 - 33, 2007.

[10] Van der Rhdd, b., Verma, R. and Plaschka G. Understanding trade-offs in the supplier selection process: The role of flexibility, delivery, and value added service/support. International Journal of
Production Economics (in press available online, 2009.

[11] Kannan A. and Noorul Haq A. Analysis of interactions of criteria and sub-criteria for the selection of supplier in the built-in-order supply chain environment. International Journal of Production Research. 45 (17), pp. 3831-3852, 2007.

[12] Wang Y-M., Luo Y., Hua Z., On The Extent Analysis Method For Fuzzy AHP And its Application, European Journal Of Operational Research, 2007, pp.735-747, 2007.

[13] Ertugtul I., Karakasoglu N. Comparison of fuzzy AHP and fuzzy TOPSIS methods for facility location selection. International Journal Adv MAnuf Technol. 2008.

[14] Sanayei A., Mousavi S. F., Abdi M.R. and Mohaghan A. An integrated group decision-making process for supplier selection and order allocation using multi-attribute utility theory and linear programming. Journal of Franklin Institute, Vol. 345, pp. 731-747, 2008.

[15] Wu W-Y, Sukoco B. M., Li C-Y and Chen S. H. An integrated multiobjective decision-making process for supplier selection with bundling problem. Experts systems with applications, Vol. 36, pp. 2327-2337, 2009.

[16] Lee A.H.I, Kang H-Y and Chang C-T Fuzzy multiple goal programming applied to TFT-LCD supplier selection by downstream manufactures. Experts systems with applications, Vol. 36, pp. $7917-$ 7927, 2009.

[17] Amid A., Ghodsypour S.H. and O'Brien C. A weighted additive fuzzy multiobjective model for the supplier selection problem under price breaks in supply chain. International Journal of Production Research, (in press, available online), 2009.

[18] Onut S., Kara S.S. and Isik E. Long-term supplier selection using a combined fuzzy MCDM approach: A case study for a telecommunication company. Expert systems with applications, Vol. 36, pp. 3887-3895, 2009. 


\begin{tabular}{|c|cc|cccc|cc|}
\hline Delivery id & \multicolumn{2}{|c|}{$\mathrm{S}_{2}$} & \multicolumn{2}{c}{$\mathrm{S}_{3}$} & \multicolumn{2}{c|}{$\mathrm{S}_{4}$} & \multicolumn{2}{c|}{$\mathrm{S}_{6}$} \\
\hline Delivery 1 & (II, b, 1) & VH & (II, a, 2) & VH & (II, b, 2) & M & (II, b, 2) & M \\
Delivery 2 & (II, a, 2) & VH & (I, a, 1) & VH & (I, a, 1) & VH & (I, a, 1) & VH \\
Delivery 3 & (II, b, 2) & M & (II, b, 2) & M & (II, b, 1) & VH & (II, b, 1) & VH \\
Delivery 4 & (II, b, 2) & M & (I, a, 1) & VH & (II, b, 1) & VH & (II, b, 2) & M \\
Delivery 5 & (II, b, 2) & M & (II, b, 2) & M & (II, b, 1) & VH & (II, b, 2) & M \\
Delivery 6 & (II, b, 2) & M & (I, a, 1) & VH & (I, a, 1) & VH & (II, b, 1) & VH \\
Delivery 7 & (II, a, 2) & VH & (II, a, 2) & VH & (II, b, 2) & M & (II, b, 1) & VH \\
Delivery 8 & (II, a, 1) & VH & (I, a, 1) & VH & (II, b, 1) & VH & (II, b, 2) & M \\
Delivery 9 & (II, a, 2) & VH & (II, b, 1) & VH & (II, a, 2) & VH & (II, b, 2) & M \\
Delivery 10 & (II, a, 1) & VH & (II, b, 2) & M & (II, b, 2) & M & (II, b, 2) & M \\
Delivery 11 & (II, b, 2) & M & (II, b, 2) & M & (II, b, 2) & M & (II, b, 1) & VH \\
Delivery 12 & (II, a, 2) & VH & (II, a, 2) & M & (I, a, 1) & VH & (II, b, 1) & VH \\
Delivery 13 & (II, b, 1) & VH & (II, b, 1) & VH & (II, b, 1) & VH & (II, b, 1) & VH \\
Delivery 14 & (I, a, 1) & VH & (II, a, 2) & VH & (I a, 1) & VH & (II, b, 2) & M \\
\hline
\end{tabular}

Table 17: Quality linguistics evolution values

\begin{tabular}{|c|c|c|c|c|}
\hline Delivery id & $\mathrm{S}_{2}$ & $\mathrm{~S}_{3}$ & $\mathrm{~S}_{4}$ & $S_{6}$ \\
\hline Delivery 1 & $(0.4,0.6,0.8)$ & $(0.4,0.6,0.8)$ & $(0.7,0.93,1)$ & $(0.7,0.93,1)$ \\
\hline Delivery 2 & $(0.7,0.93,1)$ & $(0.4,0.6,0.8)$ & $(0.7,0.93,1)$ & $(0.4,0.6,0.8)$ \\
\hline Delivery 3 & $(0.7,0.93,1)$ & $(0.7,0.93,1)$ & $(0.4,0.6,0.8)$ & $(0.7,0.93,1)$ \\
\hline Delivery 4 & $(0.7,0.93,1)$ & $(0.7,0.93,1)$ & $(0.4,0.6,0.8)$ & $(0.7,0.93,1)$ \\
\hline $\begin{array}{l}\text { Average value } \\
\text { after } 3 \text { months }\end{array}$ & $(0.625,0.845,0.95)$ & $(0.55,0.765,0.9)$ & $(0.55,0.765,0.9)$ & $(0.625,0.85,0.95)$ \\
\hline Delivery 5 & $(0.4,0.6,0.8)$ & $(0.7,0.93,1)$ & $(0.4,0.6,0.8)$ & $(0.7,0.93,1)$ \\
\hline Delivery 6 & $(0.7,0.93,1)$ & $(0.7,0.93,1)$ & $(0.7,0.93,1)$ & $(0.4,0.6,0.8)$ \\
\hline Delivery 7 & $(0.7,0.93,1)$ & $(0.4,0.6,0.8)$ & $(0.7,0.93,1)$ & $(0.7,0.93,1)$ \\
\hline $\begin{array}{l}\text { Average value } \\
\text { after } 6 \text { months }\end{array}$ & $(0.6,0.82,0.93)$ & $(0.6,0.82,0.93)$ & $(0.6,0.82,0.93)$ & $(0.6,0.82,0.93)$ \\
\hline Delivery 8 & $(0.7,0.93,1)$ & $(0.7,0.93,1)$ & $(0.7,0.93,1)$ & $(0.7,0.93,1)$ \\
\hline Delivery 9 & $(0.4,0.6,0.8)$ & $(0.4,0.6,0.8)$ & $(0.7,0.93,1)$ & $(0.4,0.6,0.8)$ \\
\hline Delivery 10 & $(0.7,0.93,1)$ & $(0.7,0.93,1)$ & $(0.4,0.6,0.8)$ & $(0.4,0.6,0.8)$ \\
\hline Delivery 11 & $(0.7,0.93,1)$ & $(0.7,0.93,1)$ & $(0.7,0.93,1)$ & $(0.7,0.93,1)$ \\
\hline $\begin{array}{l}\text { Average value } \\
\text { after } 9 \text { months }\end{array}$ & $(0.625,0.85,0.95)$ & $(0.625,0.85,0.95)$ & $(0.625,0.85,0.95)$ & $(0.55,0.765,0.9)$ \\
\hline Delivery 12 & $(0.4,0.6,0.8)$ & $(0.4,0.6,0.8)$ & $(0.4,0.6,0.8)$ & $(0.4,0.6,0.8)$ \\
\hline Delivery 13 & $(0.7,0.93,1)$ & $(0.7,0.93,1)$ & $(0.4,0.6,0.8)$ & $(0.7,0.93,1)$ \\
\hline Delivery 14 & $(0.4,0.6,0.8)$ & $(0.4,0.6,0.8)$ & $(0.7,0.93,1)$ & $(0.7,0.93,1)$ \\
\hline $\begin{array}{l}\text { Average value } \\
\text { after } 12 \text { months }\end{array}$ & $(0.5,0.71,0.86)$ & $(0.5,0.71,0.86)$ & $(0.5,0.71,0.86)$ & $(0.6,0.82,0.93)$ \\
\hline
\end{tabular}

Table 18: Quality fuzzy values 